\title{
Nilotinib as the First Line Therapy in Managing Chronic Myelogenous Leukemia
}

\section{Yuswanto Setyawan}

Faculty of Medicine, Ciputra University, Surabaya, Indonesia

Email: yuswanto_setyawan@yahoo.com

\begin{abstract}
Abstrak: Leukemia mieloid kronis (chronic myeloid leukemia/CML) adalah penyakit klonal dari sel induk hematopoietik, secara sitogenetik ditandai dengan adanya kromosom Philadelphia $(\mathrm{t}[9,22][\mathrm{q} 34 ; \mathrm{q} 11])$, yang merupakan fusi BCR-ABL1 onkogen. Nilotinib, generasi kedua inhibitor kinase tirosin, merupakan turunan aminopirimidin yang menghambat aktivitas kinase tirosin protein BCR-ABL. Dengan aktivitas penghambatan yang 10-60 kali lebih besar daripada imatinib, pada terapi lini pertama standar untuk CML, nilotinib efektif untuk CML fase kronik dan akselerasi yang resisten terhadap imatinib, namun terapi kombinasi nilotinib dengan agen lainnya masih diperlukan untuk pasien dengan CML krisis blas. Nilotinib aktif terhadap beberapa mutan BCR-ABL yang resisten terhadap imatinib, kecuali mutan T315I. Mutasi spesifik E255K/V, Y253H/F, F359C/V, dan L248V umumnya kurang sensitif terhadap nilotinib. Sebagai terapi lini pertama pada pasien CML fase kronik dengan $\mathrm{Ph}+$ yang baru terdiagnosis, nilotinib menunjukkan CCyR dan MMR yang lebih tinggi serta pengembangan menjadi fase akselerasi/krisis blas serta resiko kematian yang lebih rendah, bila dibandingkan dengan imatinib. Simpulan penelitian ini ialah nilotinib lebih unggul dibandingkan dengan imatinib sebagai terapi lini pertama pada pasien CML fase kronik dengan $\mathrm{Ph}+$ yang baru terdiagnosis,
\end{abstract}

Kata kunci: chronic myeloid leukemia (CML), nilotinib, imatinib, terapi lini pertama

\begin{abstract}
Chronic myeloid leukemia (CML) is a clonal disease of the hematopoietic stem cells, cytogenetically characterized by Philadelphia chromosome (t[9,22][q34;q11]) leading to the fusion of BCR-ABL1 oncogene. Nilotinib, the second-generation tyrosine kinase inhibitor (TKI), is an aminopyrimidine derivative that inhibits the tyrosine kinase activity of the chimeric protein BCR-ABL. Its inhibitory activity is 10-60 times that of imatinib, therefore, as the standard firstline therapy for CML, nilotinib is effective in the case of CML-CP and CML-AP with imatinib resistant or intolerant. Albeit, novel approaches with nilotinib-based combinations are required for patients in CML-BP. Nilotinib is active against several imatinib-resistant BCR-ABL mutants with the exception of T315I. Specific mutations that are less sensitive to nilotinib include E255K/V, $\mathrm{Y} 253 \mathrm{H} / \mathrm{F}, \mathrm{F} 359 \mathrm{C} / \mathrm{V}$, and L248V. As the first-line therapy of patients with newly diagnosed $\mathrm{Ph}+$ CML-CP, nilotinib has higher rates of CCyR and MMR, lower rates of progression to AP or BC, and lower risk of CML related death when compared with imatinib. In conclusion, nilotinib is superior to imatinib as the the first-line therapeutic option in newly diagnosed $\mathrm{Ph}+\mathrm{CML}-\mathrm{CP}$ patients.
\end{abstract}

Keywords: chronic myeloid leukemia (CML), nilotinib, imatinib, first line therapy

\section{Introduction}

Chronic myeloid leukemia (CML) is a disease of hematopoietic stem cells characterized by a large accumulation of myeloid cells in the bone marrow, peripheral blood, and spleen. The etiopathogenesis of CML iss linked to the so called Philadelphia chromosome resulted from a reciprocal translocation between chromosome 9 and chromosome 22 (coded as t[9,22][q34;q11]), leading to the fusion of the Breakpoint Cluster Region (BCR) gene with the 
Abelson Tyrosine Kinase (ABL1) protooncogene and the formation of the BCRABL1 oncogene, whose constitutive kinase activity drives aberrant cell growth. ${ }^{1,2}$ Typically, this kinase carefully regulates downstream targets including c-Myc, Akt, and Jun; all of which are seminal to the proliferation and survival of normal cells. However, the hyperactivity of the BCRABL kinase disrupts this fine balance and pushes cells toward uncontrolled proliferation and survival, both of which provide a growth advantage to the malignant cells bearing this mutation and ultimately leading to the pathogenesis of CML.,

The remarkable reliance of CML cells on BCR-ABL1 kinase activity has provided a molecular target for the development of pharmacologic strategies aimed at inhibiting the kinase activity of this oncogenic enzyme. A series of small-molecule compounds termed tyrosine kinase inhibitors (TKI) have been developed to prevent the access of ATP to the catalytic domain of the enzyme. ${ }^{5}$

The first generation TKI, imatinib mesylate, is the standard first-line therapy for CML, albeit, resistance occurs in a considerable proportion of patients. ${ }^{6}$ The secondgeneration TKIs, dasatinib and nilotinib, are effective in the case of imatinib failure and active against several imatinib-resistant BCR-ABL mutants with the exception of T315I. ${ }^{5-7}$

The majority of patients in all phases are treated with imatinib, however, in Indonesia, approximately $85 \%$ of CML patients are still treated with hydroxyurea whereas only $15 \%$ of patients are treated with imatinib. In general, Asian patients respond to imatinib treatment as well as in the west although the complete cytogenetic response (CCyR) rates may be lower than those reported from the western countries. The complete hematologic response was similar to those reported from the Caucasian patients. ${ }^{8}$

\section{Mechanism of Resistance}

Chronic myeloid leukemia, in its first stage (chronic phase, $\mathrm{CP}$ ) is characterized by indolent progression in which the disease is more susceptible to suppression by TKIs. During the CP, BCR-ABL stimulates the oncogenic events of the disease. The presence of mutations in BCR-ABL1 kinase is associated with greater likelihood of progression to advanced stages of the disease, the accelerated phase (AP), and the blastic phase (BP), which suggests enhanced genomic instability in these cells. Transition of a relatively benign CML-CP to the aggressive CML-BP is believed to be due to accumulation of additional chromosomal aberrations and mutations. The frequency of additional chromosomal abnormalities is around $7 \%$ in CML-CP and increases to $40-70 \%$ in the advanced phases of disease, as evaluated by standard cytogenetic analysis. ${ }^{9}$ This advanced stages, unfortunately, are resistant to TKIs because their formation and growth are, to some extent, independent from the BCR-ABL activity. ${ }^{1,6,10}$

Since BCR-ABL1 kinase induces genomic instability, TKIs should prevent accumulation of additional genetic changes in CML cells. In fact, imatinib diminished reactive oxygen species (ROS) and oxidative DNA damage, and reduced point mutations and other genetic aberrations in BCRABL1-positive cell lines. However, TKI treated patients with CML continue to accumulate point mutations and chromosomal aberrations eventually leading to disease relapse and/or malignant progression. ${ }^{9,11}$

There are several possible explanations for persistent genomic instability during TKI treatment. First, leukemic stem cells (LSCs) are resistant to TKIs. Second, the inhibitory effect of TKIs on BCR-ABL1 kinase-induced signaling is incomplete. Third, the possibility that genomic instability is driven by the presence of BCR-ABL1 protein, but not by its kinase activity. Fourth, the potential mutagenic effect of TKIs used for a prolonged period of time. Therefore, TKIs do not abrogate genomic instability. ${ }^{9}$

Other mechanisms that underlying resistance are, as follows: 1) increased production of BCR-ABL (through gene amplification or overexpression); 2) decreased intracellular 
levels of TKIs after changes in the expression of drug efflux or influx genes; and 3) the involvement of other pathways (eg, SRC family kinases). ${ }^{12,13}$

\section{Evaluation of Therapeutic Responses}

There are at least three levels of response in patients with CP-CML: hematologic response, cytogenetic response, and molecular response. ${ }^{1,14}$

According to the 2010 NCCN guidelines, the goal of CML therapy is to achieve complete cytogenetic response (CcyR). Achievement of CCyR is a widely accepted goal for CML therapy because cytogenetic responses have been shown to be a significant predictor for survival. Molecular monitoring is markedly more sensitive than conventional cytogenetics and is able to routinely detect much lower levels of disease. Molecular response has been found to be predictive of the duration and loss of CCyR, progression free survival (PFS), and event-free survival (EFS). ${ }^{15}$

In newly diagnosed patients treated with imatinib, hematologic response (HR) should be evaluated every two weeks until complete hematologic response (CHR) has been achieved and confirmed. A bone marrow (BM) examination with chromosome analysis (CG) should be completed at diagnosis before therapy and then every 6 months until CCyR. Once CCyR is obtained and confirmed, BM examination and PCR evaluation of the peripheral blood should be repeated every year. ${ }^{14}$ The evaluation of molecular response (MR) should be performed using quantitative PCR testing of peripheral blood cells every three months and it should continue even after complete MR because an increasing level of BCRABL transcripts should prompt a number of clinical decisions. ${ }^{16}$

The National Comprehensive Cancer Network (NCCN) and European Leukemia Net (ELN) propose different end points to define treatment failure or suboptimal response after imatinib, and thus recommend alternate approaches; at three months, if less than complete hematologic response (NCCN, ELN) or no cytogenetic response
(ELN); six months if less than PCyR or no cytogenetic response (NCCN, ELN); 12 months PCyR or less (NCCN, ELN); and 18 months if less than CCyR (NCCN, ELN) or $\operatorname{MMR}(\mathrm{ELN}) .{ }^{15}$

\section{Nilotinib}

Nilotinib is an aminopyrimidine derivative that inhibits the tyrosine kinase activity of the chimeric protein BCR-ABL. The chemical structure of nilotinib preserves the aminopyrimidine and amide pharmacophores of imatinib but incorporates substituents alternative to the highly basic $\mathrm{N}$ methyl-piperazine of imatinib, thereby leading to greater lipophilicity. These structural features not only result in tighter binding to the tyrosine kinase domain of BCR-ABL but also increase nilotinib concentrations in whole cells to levels higher than those found with imatinib, increase selectivity for the ABL protein, and has less cross reactivity with KIT and PDGFR. ${ }^{17}$ Nilotinib acts via competitive inhibition at the adenosine triphosphate (ATP)-binding site of the BCR-ABL protein in a similar manner to imatinib. ${ }^{18}$ Once bound to the ATP-binding site, nilotinib inhibits tyrosine phosphorylation of proteins involved in BCR-ABL-mediated intracellular signal transduction. ${ }^{19-21}$

The inhibitory activity of nilotinib in CML cell lines is markedly higher than that of imatinib. In imatinib-sensitive CML cell lines, the inhibitory activity of nilotinib is 10-60 times that of imatinib. ${ }^{1,16,22}$ Nilotinib inhibits BCR-ABL autophosphorylation with $50 \%$ inhibitory concentration (IC50) values ranging from $20-60 \mathrm{nmol} / 1$, compared to $250-280 \mathrm{nmol} / 1$ for imatinib. ${ }^{23,24}$ Drug concentrations of $<100 \mathrm{nmol} / \mathrm{l}$ show antiproliferative activity against several cell lines containing BCR-ABL point mutants commonly seen in patients with imatinib resistance. ${ }^{17}$ Nilotinib was effective in patients with a range of BCR-ABL mutations associated with imatinib resistance, other than T315I. ${ }^{6,12,19,25}$ But there exist a number of specific mutations that are less sensitive to nilotinib; these mutations include E255K/V, Y253H/F, F359C/V, and 


\section{L248V. 5,16,19,26,27}

Nilotinib has no significant activity toward Src at concentrations $<3000 \mathrm{nM}^{25,28}$ Nilotinib inhibits Src based on IC50 value $>5000 \mathrm{nM} .{ }^{11}$ These Src family of kinases are key signaling members in normal hematopoiesis and are expressed only in hematopoietic cells. These kinases are critical for the development and survival of all blood cell lineages and B lymphocytes. Therefore, nilotinib, which does not inhibit the Src family of kinases, has a more favorable myelosuppression profile. ${ }^{26}$

With once-daily dosing at steady state, nilotinib exposure is nearly dose proportional over the dose range of 50-400 mg, but no appreciable further increase in nilotinib exposure is seen at dose levels $>400 \mathrm{mg}$, suggesting dose dependent absorption of nilotinib. In a comparison of once daily and twice-daily regimens, a regimen of $400 \mathrm{mg}$ twice daily resulting in an increase of $\sim 35 \%$ in nilotinib exposure relative to a regimen of $800 \mathrm{mg}$ once daily, indicating that splitting the patient's daily dose could partially overcome the dose-related limitation on absorption. The half-life of nilotinib is 15 h. ${ }^{16}$ Since food may affect nilotinib absorbtion, it is approved at a schedule of $400 \mathrm{mg}$ twice daily without food for 2 hours before and 1 hour after administration. ${ }^{24,29}$

Therapy with nilotinib is very well tolerated. The most commonly observed treatment-related nonhematologic AEs are rash, pruritus, and nausea. ${ }^{22}$ The most common hematological toxicities include neutropenia and thrombocytopenia. Nonhematological toxicity is usually mild, most commonly rash, diarrhea, nausea, fatigue, and headache. Biochemical laboratory abnormalities include elevated lipase, elevated total bilirubin levels, hypophosphatemia, and hyperglycemia. Usually biochemical abnormalities are transient and without associated clinical symptoms. Elevated bilirubin levels are most commonly due to unconjugated bilirubin. The (TA)7 polymorphism of the promoter region of the gene of uridine diphosphate glucuronosyltransferase 1A1 (UGT1A1), the enzyme responsible for glucoronidation of bilirubin in humans, is clinically associated with Gilbert's syndrome and the development of nilotinib induced hyperbilirubinemia. Most of the time, toxicities induced by nilotinib are managed with temporary interruptions and dose reductions as necessary. Cardiac adverse events, including congestive heart failure, left ventricular dysfunction, QT prolongation, and sudden deaths have been reported. ${ }^{24}$

\section{Clinical Results with Nilotinib Phase I Trial}

A phase I dose escalation study in patients with CML and Ph+-ALL that were imatinib-resistant evaluated the safety and tolerability of nilotinib. A total of 119 patients $(\mathrm{CP}=17, \mathrm{AP}=56, \mathrm{BP}=33, \mathrm{Ph}+-$ $\mathrm{ALL}=13$ ) were treated with doses of nilotinib ranging from 50 to $1200 \mathrm{mg}$ once daily and 400 to $600 \mathrm{mg}$ twice daily. ${ }^{18}$ All concentrations reached steady-state level $(1.0 \mu \mathrm{M}$ at $400 \mathrm{mg}$ daily, $1.7 \mu \mathrm{M}$ at $400 \mathrm{mg}$ twice daily, and $2.3 \mu \mathrm{M}$ at $600 \mathrm{mg}$ twice daily), exceeding the IC50 of phosphorylation of 32 out of 33 BCR-ABL mutants. In this trial, no differences in responses were observed between patients with or without BCR-ABL mutations (except two patients with T315I mutation who exhibited resistance to nilotinib). ${ }^{30}$

Complete haematologic response (CHR) occurred in $92 \%$ of CP patients. Nine out of $17 \mathrm{CP}$ patients $(53 \%)$ achieved a cytogenetic response (six patients CCyR and three patients minimal response). Among AP patients, $72 \%$ of those with hematologic disease obtained a CHR. Cytogenetic response was obtained in $55 \%$ of patients (complete in 8 patients, partial in 7 and minor in 5). Forty-two percent of myeloid BP patients achieved a CHR and 29\% a cytogenetic response (1 patient CCyR); of the 9 patients with lymphoid $\mathrm{BP}$ or $\mathrm{Ph}+$ ALL, 33\% achieved a CHR and 22\% a cytogenetic response (1 patient CCyR). ${ }^{30}$

Data from the nilotinib phase I study showed that a single daily dose of $400 \mathrm{mg} / \mathrm{d}$, (50\% of the standard dose) achieving a steady state approximately 50 -fold of the minimum concentration was needed to 
inhibit BCR-ABL exceeding the IC50 for inhibition of most mutant forms of BCRABL (19-709 nmol/l). ${ }^{18}$

Nilotinib $400 \mathrm{mg}$ twice daily showed a favorable safety profile and produced hematologic and cytogenetic responses, including complete hematologic remissions. The efficacy and safety of nilotinib $400 \mathrm{mg}$ twice daily was further confirmed in the subsequent phase II study. ${ }^{17}$

\section{Phase II Trial}

Following the results of the phase I study, several phase II studies were designed to evaluate the efficacy of nilotinib in patients with CML who were resistant or intolerant to imatinib. Patients were treated with nilotinib at a dose of $400 \mathrm{mg}$ twice daily with the option of escalating the dose to $600 \mathrm{mg}$ twice daily if responses were inadequate. The $\mathrm{CP}$ study recruited 321 patients (71\% imatinib-resistant). After 2 years follow-up, the McyR was 58\% (CCyR $42 \%$ ). Responses were durable, and $84 \%$ of patients who achieved McyR were maintaining their response at 18 months. Responses were observed in patients with and without BCR-ABL1 mutations. Overall survival (OS) at 18 months was 91\%. ${ }^{14,16,30}$ The estimated rate of OS and PFS at 48 months was $78 \%$ and $57 \%$, respectively. After a minimum follow-up of 48 months, nilotinib continued to be effective and well tolerated in one-third of patients with CML-CP with imatinib resistance or intolerance. ${ }^{24,26}$

In the AP study, 138 patients were enrolled; $80 \%$ were imatinib resistant. The HR rate was $56 \%$, with a CHR obtained in $30 \%$. At 1 year, $78 \%$ of patients maintained their HR. McyR and CCyR occurred in 32\% and $19 \%$ of patients, respectively. Responses were durable, with $66 \%$ of patients maintaining MCyR at 24 months. ${ }^{16,18,21}$ Estimated OS at 1 year was $82 \%$. The estimated overall and progression-free survival rates at 24 months were $70 \%$ and $33 \%$, respectively. ${ }^{21}$ In the AP study, grade 3/4 neutropenia and thrombocytopenia were each observed in $42 \%$ of patients. Non-hematologic adverse events were mostly mild to moderate; the safety profile of nilotinib had not changed with longer follow-up. In all, 20 $(15 \%)$ patients remained on study at data cutoff. In summary, nilotinib has a manageable safety profile, and could provide favorable long-term outcomes in the pretreated CML-AP patient population for whom treatment options were limited. ${ }^{21}$

In this study, $400 \mathrm{mg}$ of nilotinib was administered twice daily to the patients with myeloid (MBP, $n=105$ ) or lymphoid blastic phase (LBP, $n=31$ ) CML. After a minimum follow-up of 24 months, major hematologic responses were observed in $60 \%$ (MBP) and $59 \%$ (LBP) of patients. Major cytogenetic responses (MCyR) were attained in $38 \%$ (MBP) and 52\% (LBP) of patients; and complete cytogenetic responses in $30 \%$ and $32 \%$, respectively. Median duration of MCyR was 10.8 (MBP) and 3.2 months (LBP). Median overall survival was 10.1 (MBP) and 7.9 (LBP) months with 12- and 24-month survival of $42 \%$ (MBP $44 \%$, LBP $35 \%$ ) and $27 \%$ (MBP 32\%, LBP 10\%), respectively. Twelve MBP patients and two LBP patients received subsequent stem cell transplantation. Myelosuppression was frequent, with grade $3 / 4$ neutropenia, thrombocytopenia, and anemia in $68 \%, 63 \%$, and $47 \%$ of patients, respectively. Grade 3/4 hypophosphatemia, hyperbilirubinemia, and lipase elevation were observed in $15 \%$, $11 \%$, and $11 \%$ of patients, respectively. Nilotinib has significant efficacy in patients with BP CML, but given the limited longterm survival of these patients. ${ }^{26}$

\section{ENACT Study}

Expanding Nilotinib Access in Clinical Trials (ENACT), an open-label multicenter phase IIIb study of oral nilotinib in adult patients with imatinib-resistant or intolerant CML in accelerated phase or blast, was conducted at 310 centers to evaluate the safety of nilotinib in a large patient population worldwide. More than 1600 patients were enrolled, with median age 53 years, and $69 \%$ were imatinib-resistant. ${ }^{30}$ All patients received oral nilotinib at a dose of $400 \mathrm{mg}$ twice daily. Nilotinib therapy resulted in CHR in $22.1 \%$ of patients with CML-AP and $8.4 \%$ of patients with CML- 
BC (MBC, 6.8\%; LBC, 14.0\%). An MCyR was achieved in $19.3 \%$ of patients with CML-AP, with $11.0 \%$ achieving a CCyR. Similarly, $19.5 \%$ of patients with CML-BC achieved an MCyR (MBC, 14.3\%; LBC, $36.0 \%$ ), with $12.6 \%$ achieving CCyR (MBC, 8.3\%; LBC, 26.0\%). At 18 months, the estimated overall survival rate was $81 \%$ (95\% CI: $70-89 \%$ ) for the at-risk CML-AP population and $63 \%$ (95\% CI: $51-72 \%$ ) for the at-risk CML-BC population. ${ }^{31}$

The majority of adverse effects (AEs) were hematologic, with the most common grade 3/4 hematologic toxicities being thrombocytopenia (22\%) and neutropenia (13\%). Non-hematologic AEs were mostly mild to moderate and included headache, rash, and nausea. Deaths were reported for 28 patients (3\%), and occurred more frequently among those with $\mathrm{BC}(\mathrm{n}=15)$. A low incidence of QT prolongation $(\mathrm{QTcF}$ $>500$ msec, $\mathrm{n}=2,0.2 \%$ ) was observed overall. ${ }^{30}$

\section{ENESTnd Study}

Evaluating Nilotinib Efficacy and Safety in Clinical Trials Newly Diagnosed Patients (ENESTnd) is an international, open-label, randomized study comparing the efficacy and safety of nilotinib 300 and $400 \mathrm{mg}$ twice daily and imatinib $400 \mathrm{mg}$ once daily in patients with newly diagnosed $\mathrm{Ph}+\mathrm{CML}-\mathrm{CP}$. Nilotinib demonstrated superior efficacy to imatinib with significantly faster and higher rates of complete cytogenetic response (CCyR) and major molecular response (MMR). Nilotinib was associated with a significantly lower probability of progression to accelerated phase/ blast crisis vs imatinib (two (0.7\%) progressions on nilotinib 300mg twice daily, three $(1.1 \%)$ on nilotinib $400 \mathrm{mg}$ twice daily, and $12(4.2 \%)$ on imatinib). When considering progressions occurring after study treatment discontinuation, the advantage of nilotinib over imatinib in preventing progression remained significant nine $(3.2 \%)$ progressions on nilotinib $300 \mathrm{mg}$ twice daily, six $(2.1 \%)$ on nilotinib $400 \mathrm{mg}$ twice daily, and $19(6.7 \%)$ on imatinib. Both nilotinib and imatinib were well tolerated. ${ }^{1,32,33}$
Grade 3/4 thrombocytopenia occurred at a similar frequency in all arms, whereas grade 3/4 neutropenia occurred more frequently in the imatinib arm. Different patterns of nonhematologic AEs of any grade were seen for nilotinib and imatinib, including fewer gastrointestinal (nausea, diarrhea, and vomiting), muscle spasm and fluid retention (peripheral edema, eyelid edema and periorbital edema) with nilotinib were more common than with imatinib, whereas dermatologic AEs (rash, pruritus and alopecia) and headache were more common with nilotinib. Pleural effusion occurred in $0-<1 \%$ in each arm. Rates of grade 3/4 nonhematologic AEs were low in all arms. However, rates of several biochemical abnormalities were higher with nilotinib compared with imatinib, including grade 3/4 elevations in alanine aminotransferase, bilirubin, lipase, and glucose. At the 24-month data cut-off, one patient in the imatinib arm and no patient in the nilotinib arms had experienced a QT interval prolongation to $4500 \mathrm{~ms}^{11,16}$

\section{MDACC Study and GIMEMA Working Party}

Data from the M. D. Anderson Cancer Center (MDACC) study showed high rates of cytogenetic and molecular responses (including complete molecular responses [CMRs]) in patients with newly diagnosed CML-CP $(n=74)$ treated with nilotinib 400 mg twice daily. A high rate of CCyR was observed soon after the initiation of treatment; a 98\% CCyR rate was attained with $\geq 3$ months of follow-up. A MMR rate of $88 \%$ (CMR rate of $22 \%$ ) observed with nilotinib was higher than that observed with historical controls of imatinib. Nilotinib was generally well tolerated, with the most common adverse events including fatigue, pain, rash, and elevated liver enzymes. The incidence of grade 3/4 adverse events was generally low. ${ }^{26}$

In another phase II study of nilotinib in patients with newly diagnosed CML-CP conducted by the GIMEMA Working Party, nilotinib treatment resulted in 1-year CCyR and MMR rates of $96 \%$ and $85 \%$, respec- 
tively. Overall, toxicities were minimal and mostly grade 1 , resulting in no dose interruptions and preserved quality of life. ${ }^{11,16}$

The results of both MDACC and GIMEMA studies showed that nilotinib in early CP patients induced cytogenetic and molecular responses substantially faster than those obtained with imatinib. ${ }^{30}$

\section{Potential Benefit of Nilotinib in Clinical Setting}

As BCR-ABL is the driving force behind $\mathrm{CML}$ disease progression, more effective BCR-ABL inhibition may decrease the risk of disease progression. A more potent BCR-ABL1 kinase inhibitor was hypothesized to reduce the reservoir of leukemic cells in patients, thereby impeding the emergence of drug resistance. ${ }^{34}$

For patients who have treatment failure with imatinib, second-line options should be explored. Nilotinib is highly effective and approved for the treatment of patients with CML-CP or CML-AP who are resistant to or intolerant of imatinib therapy, inducing rapid and durable hematologic and cytogenetic responses. ${ }^{16}$ Nilotinib is approved in more than 60 countries worldwide for the treatment of newly diagnosed patients with $\mathrm{Ph}+\mathrm{CML}$ in the chronic phase (CP) and in patients with $\mathrm{Ph}+\mathrm{CML}-\mathrm{CP}$ and in the accelerated phase (AP) who have failed prior therapy, including imatinib. Approval as second-line treatment was based on results from a phase II open-label registration study that showed durable responses and overall survival of $87 \%$ with 24 months of follow-up. ${ }^{34}$ With estimated 48-month OS and PFS rates of $78 \%$ and $57 \%$, respectively, second-line nilotinib was confirmed to be an effective long-term treatment option for some patients with CML-CP who are resistant to or intolerant of imatinib therapy. ${ }^{26}$

The currently reported data show that nilotinib can also induce durable hematologic and cytogenetic responses in some patients with BP. These responses may be of particular value in allowing patients to receive SCT. However, in the absence of $\mathrm{SCT}$, most responses are not durable, and novel approaches are required for patients in BP. Nilotinib-based combinations, for example, with stem-cell-modifying agents, such as smoothened inhibitors, p53 stabilization with human homolog double minute 2 inhibitions, aurora kinase inhibitors, or autophagy modifiers, would seem worthy. ${ }^{26,35}$

Recent studies have demonstrated that first-line treatment with dasatinib or nilotinib results in higher rates of CCyR and MMR by 12-24 months compared with imatinib, in addition to a lower rate of disease progression. ${ }^{11}$ Rates of progression to AP or blood crisis (BC) are significantly lower among patients treated with nilotinib compared with those treated with imatinib. Also, the risk of CML related death was lower for patients treated with nilotinib compared with patients treated with imatinib. Taken together, these data suggest that nilotinib is superior to imatinib for the treatment of patients with newly diagnosed $\mathrm{Ph}+\mathrm{CML}-\mathrm{CP}$ and should be preferred as the first-line therapeutic option for this population. $^{20,33}$

On the basis of the results from the ENESTnd clinical trial, in January 2011, nilotinib was approved by the European Medicines Agency (EMEA) for the first-line therapy of newly diagnosed $\mathrm{Ph}+$ chronic phase CML. ${ }^{1}$ Currently, nearly $40 \%$ of physicians would choose either nilotinib or dasatinib as first-line treatment. ${ }^{15}$

\section{Conclusion}

For patients who have treatment failure with imatinib, nilotinib are highly effective, inducing rapid and durable hematologic and cytogenetic responses. Nilotinib approved for the treatment of patients with CML-CP or CML-AP who are resistant to or intolerant of imatinib therapy. However, novel approaches with nilotinib-based combinations are required for patients in blast phase (BP).

As the first-line treatment of patients with newly diagnosed $\mathrm{Ph}+\mathrm{CML}-\mathrm{CP}$, nilotinib has higher rates of $\mathrm{CCyR}$ and $\mathrm{MMR}$, lower rates of progression to AP or $\mathrm{BC}$, lower risk of CML related death, when compared with imatinib. Nilotinib is supe- 
rior to imatinib for the treatment of patients with newly diagnosed Ph+ CML-CP and should be preferred as the first-line therapeutic option for this population.

\section{Conflict of Interest}

The author affirms no conflict of interest in this study.

\section{REFERENCES}

1. Leonetti F, Stefanachi A, Nicolotti O, Catto M, Pisani L, Cellamare S, et al. BCR-ABL inhibitors in chronic myeloid leukemia: process chemistry and biochemical profile. Curr Med Chem. 2011;18(19): 2943-59.

2. Traer E, Deininger MW. How much and how long: tyrosine kinase inhibitor therapy in chronic myeloid leukemia. Clin Lymphoma Myeloma Leuk. 2010;10(1): S20-S26.

3. Jabbour E, Fullmer A, Cortes JE, Kantarjian H. Clinical algorithms for the treatment of patients with chronic myeloid leukemia: the 2010 perspective. Clin Lymphoma Myeloma Leuk. 2010;10(1): S6-S13.

4. Cornelison AM, Kantarjian H, Cortes J, Jabbour E. Outcome of treatment of chronic myeloid leukemia with second-generation tyrosine kinase inhibitors after imatinib failure. Clin Lymphoma Myeloma Leuk. 2011;11(S1):S101-10.

5. Cardama AQ, Cortés JE. The next generation of therapies for chronic myeloid leukemia. Clin Lymphoma Myeloma. 2009;9(4): S395-S403.

6. Meggyesi N, Kozma A, Halm G, Nahajevszky S, Bátai A, Fekete S, et al. Additional chromosome abnormalities, BCR-ABL tyrosine kinase domain mutations and clinical outcome in Hungarian tyrosine kinase inhibitor-resistant chronic myelogenous leukemia patients. Acta Haematol 2012;127:34-42.

7. Giles FJ, Dwyer MO, Swords R. Class effects of tyrosine kinase inhibitors in the treatment of chronic myeloid leukemia. Leukemia 2009;23(10):1698-707.

8. Jootar S. CML treatment in Asia-Pacific region. Hematology. 2012;17(1): S72-S74.

9. Skorski T. Chronic myeloid leukemia cells refractory/resistant to tyrosine kinase inhibitors are genetically unstable and may cause relapse and malignant progression to the terminal disease state. Leuk Lymphoma. 2011;52(S1):23-9.

10. Deangelo DJ, Attar EC. Use of dasatinib and nilotinib in imatinib-resistant chronic myeloid leukemia: translating preclinical findings to clinical practice. Leuk Lymphoma. 2010;51(3):363-75.

11. Shami PJ, Deininger M. Evolving treatment strategies for patients newly diagnosed with chronic myeloid leukemia: the role of second-generation $\mathrm{BCR}-\mathrm{ABL}$ inhibitors as first-line therapy. Leukemia. 2012;26(2):214-24.

12. Fava C, Cortés JE, Kantarjian H, Jabbour E. Standard management of patients with chronic myeloid leukemia. Clin Lymphoma Myeloma 2009;9(Suppl4): S382-S390.

13. Giles FJ, Kantarjian HM, Coutre PD, Baccarani M, Mahon FX, Blakesley RE, et al. Nilotinib is effective in imatinibresistant or -intolerant patients with chronic myeloid leukemia in blastic phase. Leukemia. 2012;26(5):959-62.

14. Aguayo A, Couban S. State-of-the-art in the management of chronic myelogenous leukemia in the era of the tyrosine kinase inhibitors: evolutionary trends in diagnosis, monitoring and treatment. Leuk Lymphoma 2009;50(S2):1-8.

15. Kantarjian HM, Larson RA, Cortés JE, Deering KL, Mauro MJ. Current practices in the management of chronic myeloid leukemia. Clin Lymphoma Myeloma Leuk. 2013;13(1):48-54.

16. Jabbour E, Cortes JE, Kantarjian H. Secondline therapy and beyond resistance for the treatment of patients with chronic myeloid leukemia post imatinib failure. Clin Lymphoma Myeloma. 2009;9(3): S272-S280.

17. Tanaka C, Yin OQP, Sethuraman V, Smith T, Wang X, Grouss K. Clinical pharmacokinetics of the bcr-abl tyrosine kinase inhibitor nilotinib. Clin Pharmacol Ther. 2010;87(2):197-203.

18. Santos FP, Ravandi F. Advances in treatment of chronic myelogenous leukemia -new treatment options with tyrosine kinase inhibitors. Leuk Lymphoma. 2009; 50(S2):16-26.

19. Plosker GL, Robinso DM. Nilotinib. Drugs. 2008;68(4):449-59.

20. Jones KP. Nilotinib in the first-line treatment of newly diagnosed Philadelphia 
chromosome-positive chronic myeloid leukaemia in chronic phase. Drugs. 2011;71(12):1579-90.

21. Coutre PD, Giles FJ, Hochhaus A, Apperley JF, Ossenkoppele GJ, Blakesley R, et al. Nilotinib in patients with $\mathrm{Ph}+$ chronic myeloid leukemia in accelerated phase following imatinib resistance or intolerance: 24-month follow-up results. Leukemia. 2012;26(6):1189-94.

22. Saglio G, Baccarani M. First-line Therapy for chronic myeloid leukemia: new horizons and an update. Clin Lymphoma Myeloma Leuk. 2010;10(3):169-76.

23. O'Hare T, Walters DK, Stoffregen EP, Jia T, Manley PW, Mestan J, et al. In vitro activity of Bcr-Abl inhibitors AMN107 and BMS-354825 against clinically relevant imatinib resistant Abl kinase domain mutants. Cancer Res. 2005; 65(11):4500-5.

24. Santos FP, Kantarjian H, Fava C, O'Brien S, Manero GG, Ravandi F, et al. Clinical impact of dose reductions and interruptions of secondgeneration tyrosine kinase inhibitors in patients with chronic myeloid leukaemia. $\mathrm{Br} \mathrm{J}$ Haematol. 2010;150(3):303-12.

25. Giles FJ, Coutre PD, Ibarz JP, Larson RA, Gattermann N, Ottmann OG, et al. Nilotinib in imatinib-resistant or imatinib-intolerant patients with chronic myeloid leukemia in chronic phase: 48month follow-up results of a phase II study. Leukemia. 2013;27(1):107-12.

26. Giles FJ, Abruzzese E, Rosti G, Kim DW, Bhatia R, Bosly A, et al. Nilotinib is active in chronic and accelerated phase chronic myeloid leukemia following failure of imatinib and dasatinib therapy. Leukemia. 2010;24(7):1299-301.

27. Soverini S, Rosti G, Iacobucci I, Baccarani M, Martinelli G. Choosing the best secondline tyrosine kinase inhibitor in imatinib-resistant chronic myeloid leukemia patients harboring Bcr-Abl kinase domain mutations: how reliable is the IC50? Oncologist 2011;16(6):868-76.

28. Rosti G, Castagnetti F, Gugliotta G, Palandri
F, Martinelli G, Baccarani M. Dasatinib and nilotinib in imatinib-resistant Philadelphia-positive chronic myelogenous leukemia: a 'head-to-head comparison'. Leuk Lymphoma. 2010;51(4): 583-91.

29. Fava C, Kantarjian H, Cortes J. Molecular resistance: an early indicator for treatment change? Clin Lymphoma Myeloma Leuk. 2012;12(2):79-87.

30. Breccia M, Alimena G. Nilotinib therapy in chronic myelogenous leukemia: the strength of high selectivity on BCR/ ABL. Curr Drug Targets 2009;10(6): 530-6.

31. Nicolini FE, Masszi T, Shen Z, Gallagher NJ, Jootar S, Powell BL. Expanding Nilotinib Access in Clinical Trials (ENACT), an open-label multicenter study of oral nilotinib in adult patients with imatinib-resistant or -intolerant chronic myeloid leukemia in accelerated phase or blast crisis. Leuk Lymphoma. 2012;53(5):907-14.

32. Eiring AM, Khorashad JS, Morley K, Deininger MW. Advances in the treatment of chronic myeloid leukemia. BMC Med. 2011;9:99.

33. Larson RA, Hochhaus A, Hughes TP, Clark RE, Etienne G, Kim DW. Nilotinib vs imatinib in patients with newly diagnosed Philadelphia chromosomepositive chronic myeloid leukemia in chronic phase: ENESTnd 3-year followup. Leukemia. 2012; 26(10):2197-203.

34. Stein AM, Martinelli G, Hughes TP, Müller MC, Beppu L, Gottardi E, et al. Rapid initial decline in BCR-ABL1 is associated with superior responses to second-line nilotinib in patients with chronic-phase chronic myeloid leukemia. BMC Cancer 2013;13:173.

35. Grossmann V, Kohlmann A, Zenger M, Schindela S, Eder C, Weissmann S, et al. A deep-sequencing study of chronic myeloid leukemia patients in blast crisis (BC-CML) detects mutations in 76.9\% of cases. Leukemia. 2011; 25(3):557-60. 